\title{
CRESCIMENTO RELATIVO E MATURIDADE SEXUAL MORFOLÓGICA DO CAMARÃO PROCESSA HEMPHILLI MANNING \& CHACE, 1971 (CARIDEA: PROCESSIDAE) NA ENSEADA DE UBATUBA, SP, BRASIL
}

\author{
Talamonte, N.B. ${ }^{1,}$; Zapparoli, I.C. ${ }^{\text {; }}$ Carvalho-Batista, A. ${ }^{1}$ \& Costa, R.C. ${ }^{1}$ \\ ${ }^{1}$ Universidade Estadual Paulista (UNESP), Faculdade de Ciências, Campus de Bauru. \\ Laboratório de Camarões Marinhos e de Água Doce (LABCAM). \\ *Autor correspondente: natalia_bosco@hotmail.com
}

\begin{abstract}
O presente estudo tem como objetivo estimar pela primeira vez a maturidade sexual morfológica do camarão Processa hemphilli por meio da análise do crescimento relativo. Para tal, foram utilizados 75 indivíduos machos coletados na Enseada de Ubatuba $\left(23^{\circ} 25^{\prime}-23^{\circ} 27^{\prime} \mathrm{S} ; 45^{\circ} 00^{\prime}-45^{\circ} 03^{\prime} 18^{\prime \prime} \mathrm{W}\right)$ em arrastos com uma rede do tipo mini "otter trawl" (malha de $5 \mathrm{~mm}$ na panagem e 0,5 mm no copo final). Após identificação quanto ao sexo, os espécimes foram mensurados quanto ao comprimento da carapaça (CC mm), largura da carapaça (LC), largura do abdômen (LA), comprimento do própodo (Pp), carpo (Pc), mero (Pm) e dáctilo ( $\mathrm{Pd}$ ) direito e esquerdo do primeiro e segundo par de pereópodos, largura da segunda pleura abdominal (2PI) e comprimento do apêndice masculino (AM). Após as mensurações, correlacionou-se a variável independente (CC) com as demais medidas dependentes por meio de uma equação alométrica " $y=a x^{b}$ ". O tamanho da maturidade sexual morfológica estimada para os indivíduos foi de 3,1 mm CC (média = 3,56 $\pm 0,29$ ) e foi melhor evidenciado pelas relações CC x Pc direito e esquerdo do primeiro par de pereópodos. Foi constatado crescimento isométrico para os juvenis e alométrico negativo para os adultos, sendo $b=1,18 ; R^{2}=0,79$ para os juvenis e $b=0,39 ; R^{2}=0,19$ para os adultos no Pc direito e $b=0,75 ; R^{2}=0,57$ para os juvenis e $b=0,67 ; R^{2}=0,47$ para os adultos no Pc esquerdo. Esse resultado permite concluir que há um investimento energético proporcional no crescimento destas estruturas em relação à CC na fase juvenil e uma estabilização no crescimento da mesma na fase adulta. A partir dos resultados obtidos no estudo, possibilitou um maior entendimento sobre a maturidade e ontogenia de $P$. hemphilli, servindo de base para estudos futuros relacionados a outros aspectos populacionais como o recrutamento juvenil e período reprodutivo.
\end{abstract}

Palavras-chave: ontogenia, reprodução, maturidade. 